Fecha de recepción: marzo 2011 Fecha de aceptación: junio 2011 Versión final: septiembre 2012

\section{Nanociencia y Nanotecnología... un mundo pequeño}

Mario Quintili *

\begin{abstract}
Resumen: Este artículo resume el estado de desarrollo de la Nanociencia y la Nanotecnología en la actualidad. Los efectos en la educación. Los descubrimientos científicos más recientes en todas las áreas industriales aplicadas a la Nanotecnología. El desarrollo de materiales en la industria textil con la utilización de nanotecnología y nano partículas que crean estructuras nanométricas, tales como hilados, tejidos e indumentarias. Productos nanotecnológicos utilizados en las tintorerías, estamperías y lavanderías. Nuevas normas técnicas y jurídicas para el desarrollo, producción, utilización y protección de la nueva ciencia. Las ventajas y el desempeño macro y micro económicos.
\end{abstract}

Palabras clave: energía vibracional - moléculas - nano partículas - Nanociencia - Nanotecnología.

[Resúmenes en inglés y portugués en las páginas 154-155]

(*) Maestría en Química Inorgánica, con especialidad en Nanociencia y Nanotecnología. Ingeniero Textil, con especialización en hilandería, tejeduría y terminaciones especiales.

\title{
Introducción
}

En los últimos 40 años la tecnología y la ciencia rompieron su relación con el humanismo y como consecuencia de ese acto, el buen sentido de discernimiento se perdió. En ese momento hubo también una separación entre lo que se estudiaba en los colegios y lo que las universidades ofrecían en sus planes de estudios. Como consecuencia de todo este proceso, se perdió de vista la dirección que el mundo fue tomando en las últimas décadas, donde la ciencia y la tecnología fueron exigiendo con el pasar de los años, una interacción en todos los niveles: educacional, científico, político y económico, para obtener un papel fundamental en cualquier modelo de desarrollo. Lo que se está formando son seres humanos, y se corre el riesgo de que mucha tecnología tienda a deshumanizar al hombre, es sumamente importante establecer de manera muy precisa los límites entre la interacción tecnológica, científica y el humanismo.

La nanotecnología, promete ser la revolución de las revoluciones tecnológicas o mejor, la tercera revolución industrial. Se perfila como un conjunto de revoluciones tecnológicas multidisciplinarias que permitirá a la sociedad maximizar la eficiencia en los procesos productivos y sociales. La nanotecnología se define como el campo de las ciencias aplicadas dedicado al control y manipulación de la materia a una escala menor que un micrómetro, es decir, a nivel de 
átomos y moléculas. Para tener una idea de lo que estamos hablando, la medida nano equivale a 70 mil veces menos que la espesura de un cabello.

La nanotecnología alterará radicalmente varios aspectos de nuestras costumbres, no solamente de cómo vivimos y lo que consumimos, sino también la forma en que realizamos nuestros trabajos en cualquier área socio-económica. Será fundamental, con los muchos cambios que trae la nanotecnología, pensar en lo que será prioritario para un desarrollo armónico, en referencia a los avances tecnológicos y sociales, para transformarlos en calidad de vida para todos, reuniendo el espacio que separó a la tecnología del humanismo.

Las economías de las principales potencias mundiales, ya están comenzando a ser dominadas por la nanotecnología. Los países emergentes, recién se están organizando estructuralmente para permitir el desarrollo. Se calcula que en pocos años ésta moverá trillones de dólares en el mundo y hay que resaltar que toda esta evolución, ha ampliado la brecha aún más entre los países del primer mundo y aquellos emergentes.

Para que se haga presente en todos los contextos nacionales dentro de los próximos diez años y para que la nanotecnología esté implantada de una forma segura y definitiva, a pesar de lo que muchos escépticos opinan de una forma egoísta seguramente por intereses propios, debemos pensar en la necesidad de los principales cambios. Estos cambios en los países emergentes, pueden ocurrir por dos vías: por la vía académica o por la vía industrial.

La nueva ciencia desarrollada con nanotecnología tiene que tener rigurosos estudios de cómo serán las normas técnicas y jurídicas a ser empleadas, desde su desarrollo, fabricación, agregado a los productos convencionales, nano productos y defensa de los consumidores. Esto tiene que ser considerado con muchísima seriedad, por las posibles practicas ilícitas que puedan emplearse en contra de la salud y de la seguridad nacional. Por este y otros motivos, deben existir leyes claras y rigurosas contra personas inescrupulosas que puedan utilizar la nanociencia para hacer daños irreparables a la salud de las personas. Será la única forma que se podrá mantener y controlar el ritmo de los nuevos desafíos que la nanotecnología está trayendo.

Las preguntas son: ¿La Argentina se está preparando adecuadamente rumbo a esta nueva revolución?, ¿Estará lista para los nuevos desafíos?, ¿Está evolucionando adecuadamente en cada sector?, ¿Cuánto destinará financieramente?

\section{La aparición}

La nanotecnología y nanociencia existen porque hace medio siglo que los cuánticos tiraron por tierra los conceptos de la física clásica y crearon la física cuántica, donde los átomos fueron desnudados hasta entender el funcionamiento del núcleo de los electrones y los fotones. De esta manera descubrimos, que ellos son los responsables principales, donde todo comienza en términos de energía, dando lugar a la creación de una vida que no se puede ver a simple vista, en principio. La idea de utilizar estructuras atómicas construyendo átomos sobre átomos comenzó con el Dr. Richard Feynman en el año de 1952, cuando anticipó conceptos que hoy son realidad en las actividades nanotecnológicas.

El nombre Nanotecnología fue atribuido en el año de 1974 por el Prof. Norio Taniguchi de la Universidad de Ciencias de Tokio, en un articulo publicado con el siguiente titulo: "Nanotecno- 
logía consiste en el procedimiento de separación, consolidación y deformación de materiales átomo por átomo o molécula por molécula”. Durante ese año de 1974 la nanotecnología comenzó a crecer con fuerza y condujo a los científicos más optimistas a trabajar con empeño en distintos temas. La idea de que en algún sentido se podría tocar los átomos y las moléculas, surgió en la década del 80, cuando estudiosos apoyados por la teoría propuesta por el Dr. K. Eric Drexler, consiguieron manipular los átomos y las moléculas. Esto causó una gran controversia de opiniones en la época y dio hasta motivos para que la justicia intervenga por el temor de que sea usado con intenciones bélicas o ilícitas.

Los finlandeses dieron su gran colaboración a esta nueva ciencia cuando consiguieron realizar un "proceso de camadas atómicas". Este trabajo hizo que toda la comunidad científica terminase por aceptar e instaurar definitivamente la nanotecnología como una ciencia del futuro. Desde entonces el nombre Nanotecnología, viene siendo utilizado para caracterizar los nuevos avances tecnológicos desenvueltos por la nanociencia, que tiene por principio, controlar y manipular la materia en una escala menor que un micrómetro, es decir, a nivel de átomos y moléculas.

La nanociencia y la nanotecnología, abren un abanico de innumerables posibilidades, para el crecimiento de las áreas tecnológicas, científicas y económicas de cualquier país que quiera crecer.

\section{Ramificación}

Ya en los primeros años de la década del 80 hubo una evolución significativa en la nanociencia. Los principales laboratorios del mundo, tales como el de IBM, Bell, MIT, desarrollaron medios para visualizar y manipular los átomos y moléculas.

En 1985 los Profesores Kroto y Smalley, cuando estaban realizando experimentos en los que se trataba de convertir carbono gaseoso en partículas (hollín), fenómeno que se produce en las estrellas, encontraron unas nuevas estructuras estables de las cuales la más abundante fue una molécula de fórmula $\mathrm{C}_{60}$ (Carbono sesenta), la cual constituye una nueva forma de carbono. La estructura del $\mathrm{C}_{60}$ es similar a la de una pelota de fútbol (de ahí el nombre de futbolanos o buckybolas como también se les conoce) En general, se conoce con el término de fullerenos (en honor del arquitecto Buckminster Fuller).

La importancia del descubrimiento de estos tipos de moléculas, abrieron ya en el final de los años 80 , un nuevo campo de posibles aplicaciones en la elaboración de nuevos tipos de polímeros, superconductores, estructuras con metales o con otros átomos atrapados dentro de estos agrupamientos de carbono, así como nuevos catalizadores, productos farmacéuticos y otras posibles aplicaciones industriales.

Desde entonces, al ver que la nueva era nano-científica sería aplicable en las más vastas áreas de la ciencia y de la industria, fue necesario a través de los años, relacionar las áreas de estudio, para que la nueva fase nano-industrial comenzara a generar los primeros frutos de evolución, crecimiento y valor agregado en la economía mundial. 


\section{Reencontrando la interdisciplinariedad}

En este contexto fue necesario reestructurar de forma paulatina, pero firme, los planes de estudio en todos los niveles de la educación, para que los estudiantes tuviesen clases teóricas en estos temas de ciencias, de modo que al llegar a la Universidad, pudiesen decidir con más firmeza su relación con el futuro profesional. Es de esa forma que surge tan explícitamente la interdisciplinariedad, que es conocida desde 1937 y con el transcurrir del tiempo venía siendo desarrollada. Podemos citar algunas de las materias como por ejemplo la química, física, bioquímica, biología molecular, electrónica, matemática, informática, medicina, ingenierías, sociología, entre tantas otras.

$\mathrm{Al}$ involucrar investigadores, estudiantes y maestros con un mismo objetivo de vincular e integrar muchas escuelas de pensamiento, profesiones y tecnologías, en la búsqueda de un fin común, hoy encontramos nuevamente al humanismo relacionándose con la tecnología, después de años caminando por senderos opuestos.

Fue y es, sumamente importante comenzar desde los primeros pasos en la alfabetización de los pequeños en el jardín de infantes, pasando por cada uno de los niveles educativos, hasta el universitario, trabajar con el fin de desarrollar la única cosa que las máquinas jamás podrán sacarle a los seres humanos, el poder de la "creatividad". Es imprescindible para los estudiantes de hoy, al ingresar en la Universidad, continuar con la evolución en la creatividad y sumarla a la interdisciplinariedad, pues es la suma de las dos que generará en los cursos superiores, como lo son el posgrado, la maestría, el doctorado, la base para el desarrollo académico y científico. Cada vez más se dejara atrás la ciencia que trabaja con lo que se ve a simple vista, por la nanociencia que esta oculta, pero es tan real cuanto la visible que a diario palpamos y vemos.

\section{Explotando la interdisciplinariedad}

La nanociencia y nanotecnología ofrecen un gran potencial para el desarrollo de nuestros conocimientos de una manera sustentable. Para quien no tenga una visión completa de este nuevo estudio interdisciplinar, podrá entenderlo como una gran disputa de intereses sectoriales, cuando lo más importante son las discusiones éticas y técnicas de su sustentabilidad.

Hoy en día la nanociencia esta siendo estudiada en los principales laboratorios del mundo, en las más diversas ramificaciones. Actualmente el principal exponente es el Prof. K. Eric Drexler, del Massachusetts Institute of Tecnology - MIT, creador y hoy presidente del Foresight Institute, que congrega estudiosos en los temas de nanociencia y nanotecnología.

La nanotecnología ya tiene hoy un impacto en toda una gama de áreas como medicina, sector energético, agrícola, alimenticio, industrial entre tantos otros. Ahora se tendría que aprender a usarlo y direccionarlo de la mejor manera para que contribuya no solamente económicamente sino principalmente en lo social y ambiental.

El medio ambiente como uno de los macro determinantes de la salud y la vida humana no podría dejar de ser una de las principales áreas en sentir el impacto de la nanotecnología. Lamentablemente no estamos hablando de solucionar todos los perjuicios ambientales ya ocasionados por el hombre en todos estos milenios, pero por lo menos ayudar a restablecer en alguna forma gran parte de un equilibrio natural que fue quebrado por la explotación sin control de los 
recursos naturales. Con la nanotecnología habrá mucho menos necesidad de minerales lo que permitirá cerrar muchas minas que por la misma extracción ha causado muchísimos daños. La fabricación molecular auto-contenida permitiría el desarrollo rápido de tecnología que no daña al medioambiente y conseguiríamos energía solar almacenable en la gran mayoría de las casas e industrias reduciendo de este modo emisiones de ceniza, hollín, hidrocarbonos, NOx, $\mathrm{CO} 2$ y petróleo.

Podremos tener la oportunidad de intervenir en todos los niveles de gestión ambiental como por ejemplo: detectar y limpiar impurezas, monitorear y prevenir permanentemente daños en el medio ambiente, contribuir al suministro de agua potable más pura y más económica, alimentos mas seguros entre tantos otros aspectos importantes.

Uno de los puntos directos y fuertes aplicables socialmente, es en el área de la medicina. Las herramientas de la investigación y la práctica de la medicina serán menos costosas y más potentes. Investigación y diagnosis serán más eficaces, lo que permitirá una capacidad de respuesta más rápida para tratar nuevas enfermedades. Numerosos pequeños censores, chips y diversos aparatos implantables de bajo costo, permitirán un control continuo sobre la salud de pacientes así como tratamientos automáticos. Serán posibles diversos tipos de nuevos tratamientos.

\section{Un largo camino por recorrer}

Por ser una ciencia no visible y de fácil acceso entre tantos otros motivos, todavía hay mucho por hacer. Uno de los puntos académicos en el que se necesita un mayor avance, es en encontrar métodos prácticos para demostrar lo que enseñamos en la teoría. Tal vez sea ese el mayor problema por el cual no se le dio la verdadera importancia que debería tener y así se perdió de vista durante muchos años esta nueva fuente de conocimiento y avance en lo económico-social. Pensemos en la importancia y en la necesidad actual, de despertar el interés entre los docentes y estudiantes, como los principales responsables en el desarrollo de las áreas de desarrollo del país. Hasta que no comencemos a usar nuestro buen sentido común para entender los cambios que son imprescindibles hacer, los estudiantes de las universidades serán apenas graduados incompletos.

El trabajo será arduo, porque será preciso preparar profesores en la nanociencia y que tengan múltiples capacidades. Deberán saber explicar la teoría, transferir esa teoría al laboratorio y más que eso, será importantísimo que tengan valores éticos y morales incontestables, pues el hecho de manipular moléculas puede ser usado de manera ilícita. Entrar en este mundo desconocido en gran parte para algunos, tiene que convertirse en realidad ya y ahora, porque el mundo no puede esperar más.

Si evitamos pasar por alto la nanociencia, ésta será una gran oportunidad para colocar a la Argentina más próxima al nivel científico-tecnológico en que se encuentran los países del primer mundo. De no prepararnos y esforzarnos, quedaremos más retrasados todavía de la nueva revolución científica tecnológica del siglo XXl.

A simple vista parecería que el estudio de la nanociencia y nanotecnología se trata del estudio de vidas inexistentes, pero después de mucho trabajo y estudios durante décadas, hoy podemos entender que en todo lo que no vemos es donde en realidad comienza la verdadera vida, aunque esté oculta a nuestros ojos, ella existe. 


\section{¿Qué es la nanotecnología?}

Relataremos un poco sobre lo que se viene descubriendo, y ya es realidad, gracias a la nanociencia y ahora se está aplicando a través de la nanotecnología en las más diversos sectores del interés humano.

Todos estos estudios en laboratorios, llevaron a los científicos a descubrimientos importantísimos, que nos dimensionan aun más lo que es capaz de hacer la nanociencia y hacia donde nos lleva. Por ejemplo, John Mamin del laboratorio de IBM dibujó un mapa con átomos de oro para demostrar el potencial de almacenamiento de informaciones en poco espacio. La técnica de Mamin, podría llegar a almacenar toda la obra completa de William Shakespeare en un área del tamaño de 0,2 milímetros como la que tiene la cabeza de un alfiler. Un poco después, científicos del Instituto de Tecnología Technion, en Israel, escribieron todo el contenido del Viejo Testamento en una superficie de 0,5 milímetros cuadrados. Si todavía no hemos conseguido asimilar la dimensión de donde llegamos con lo de William Shakespeare o lo del Viejo Testamento, prepárense pues vamos por mucho más.

La Nanotecnología trabaja claramente con materiales estructurados en escala nanométricas o sea nanoestructuras. Estas nanoestructuras forman bloques de construcción (building blocks) como clusters, nanopartículas, nanotubos y nanofibras que a su vez se forman a partir de átomos y moléculas. Manipulando estos bloques de construcción se forman los materiales y dispositivos nanoestructurados que es el objetivo central de la nanotecnología.

Los materiales fabricados con la nanotecnología tienen menos defectos y mejor calidad. Sus propiedades son totalmente iguales, manteniendo todas las mismas cantidades de divisiones, longitud y diámetro de una forma diferente a cuando se manipula material en grandes cantidades. La nueva metodología industrial capaz de producir los nuevos productos que llegan al comercio con el nombre de nanotecnológicos ya generó en el mundo la cantidad de 450 productos que están circulando a diario de forma desapercibida por los consumidores.

\section{Clasificación de la nanotecnología}

La nanotecnología se divide en dos tipificaciones, según la técnica de aplicación: técnicas de arriba hacia abajo (Top-down) y técnicas de abajo hacia arriba (Bottom up). En el caso de la nanotecnología Top-down, se trata de diseñar $y$ miniaturizar el tamaño de estructuras para obtener a nanoescala sistemas funcionales en el caso de la producción de nanoelectrónica (miniaturización de sistemas electrónicos). Y en el caso de la nanotecnología tipo Bottom-up, se centra en la construcción de estructuras y objetos más grandes a partir de sus componentes atómicos y moleculares o sea este tipo de nanotecnología es acogida como el enfoque principal de la nanotecnología ya que permite que la materia pueda controlarse de manera extremadamente precisa. Por otra parte se puede clasificar o subdividir la nanotecnología según el ámbito de aplicación, de esta forma se puede dividir como seca y húmeda. Esta clasificación se determina según el medio en y para el cual se genera tal aplicación, el medio puede ser acuoso (nanotecnología húmeda) y el caso de la ausencia de un entorno húmedo (nanotecnología seca).

La aplicación de la nanotecnología húmeda va dirigida al desarrollo de sistemas biológicos, éstas incluyen la manipulación de material genético, membranas, enzimas y otros componentes ce- 
lulares, que están inmersos en un medio acuoso. Por parte de la nanotecnología seca, se resalta como característica su predominante aplicación en el campo de la electrónica y se puede mencionar como ejemplo el magnetismo, dispositivos ópticos y desarrollo de materiales inorgánicos.

\section{Tipos de nanotecnología}

Lo que caracteriza los campos de aplicación de la nanotecnología depende directamente de la forma, procedimiento y fin para lo que se da la manipulación de la materia en la escala nano. Estos materiales utilizados son llamados nanomateriales, los cuales pueden obtenerse del medio ambiente con sus características naturales o pueden ser generados de forma sintética a los cuales se les atribuye características especiales. A su vez los nanomateriales pueden ser subdivididos en nanopartículas, nanocapas y nanocompuestos.

\section{Diversos productos en nanotecnologías}

Con el transcurrir de los años surgieron las más distintas investigaciones en las más diversas áreas de estudio. Esto posibilitó el desarrollo de diversos nanomateriales, nanopartículas y diversas hipótesis futurísticas, que cada día que pasa ya dejan de ser hipotéticas. Todos estos productos son de grandes beneficios a la sociedad, al medio ambiente y a la industria.

Dendrímero: son moléculas tridimensionales, nanoescalares, así llamadas porque las estructuras semejan árboles con ramas (dendrones). Los dendrímeros son capaces de alojar, ya sea en las cavidades internas como así también en la superficie, pequeñas moléculas que después pueden liberarse en momentos, lo que los hace prometedores agentes de suministro de medicamentos, y agentes de suministro de perfumes y herbicidas con liberación programada según un esquema temporal.

Fago T4: su diseño está inspirado en los virus, dando vida a una máquina que tiene la capacidad de colocar sus patas sobre la superficie de las bacterias e inyectarles ADN.

Nanoalambres: son nanoestructuras en forma de filamento, recubierto de receptores biológicos específicos a determinado tipo de microorganismos y/o sustancias que al encontrarse inmerso en un medio celular puede variar su conductividad eléctrica al reconocer el agente de acuerdo al tipo de receptores en su superficie.

Nanobiosensores Fotónicos: son nanobiosensores basados en nanopartículas de oro o magnéticas que interactúan con los Quantum Dots (puntos cuánticos) de energía de la radiación electromagnética llamados fotones.

Nanobombas: son conglomeraciones de nanotubos de carbono recubiertos de anticuerpos a escala nanométrica, que una vez son expuestos a la luz y al calor resultante, son incapaces de disipar la energía concentrada y se produce una especie de explosión 
Nanosensores: dispositivos diseñados nanométricamente encargados de detectar una determinada acción externa, temperatura, presión, compuesto químico etc.

Nanomotores: los nanomotores ilustran un ejemplo de engranaje atómico realizado por ordenador. Estos son de nanotecnología Bottom-Up.

Nanotransportadores: son de gran eficacia a la hora de transportar fármacos y ADN. Lo que facilita la capacidad de dirigir con precisión un fármaco a la localización deseada en el cuerpo, tal como la de órganos particulares o células específicas.

Nanopartículas: es una pieza pequeña de materia, compuesta de un elemento particular o un compuesto de elementos. Lo típico es que midan menos de 100 nanómetros de diámetro. El término puede referirse a un amplio rango de materiales, incluida la materia particulada que expulsa el tubo de escape de un automóvil. En los últimos veinte años, las partículas diseñadas con ingeniería nanológica se fabrican con fines comerciales, con el propósito de sacarle ventaja a sus efectos cuánticos. Actualmente sé está utilizando fármacos, lubrificantes, tintas, herramientas, tejidos entre varios otros.

Nanoshells: son nanopartículas que se conforman de una delgada capa metálica generalmente de oro, de unos 8 a 10 nanómetros que recubre una estructura esférica de silicio de un diámetro aproximado de unos 100 nanómetros.

Nanocompuestos: Compuestos de metales, polímeros y materia biológica que permiten comportamiento multifuncional. Aplicados donde pureza y conductividad eléctrica importan, como microelectrónica, llantas de automóviles, equipos deportivos como raquetas y pelotas de tenis, ropa, textiles, antisépticos entre otros.

\section{Los nanotubos}

Con el descubrimiento del C $_{60}$ (carbono sesenta), Sumio Lijima descubrió en 1991 el nanotubo de carbono, que es un bloque de construcción constituido por una hoja de carbono enrollada de modo que conecta sus extremidades formando un tubo. Los nanotubos revolucionaron la nanotecnología por mostrar la resistencia mecánica altísima y propiedades para aplicaciones singulares como conductividad eléctrica y térmica. Luego en 1996 Richard Smalley desarrolló un método de producción de nanotubos de diámetros uniformes y en el 2000, científicos de la universidad de Rice desarrollaron un método para transformar nanotubos de carbono en estructuras rígidas. Hasta antes de 1985 se pensaba que solo había dos formas ordenadas de carbono elemental: el grafito y el diamante. Con el descubrimiento de los fullerenos y de los nanotubos se inicia una nueva era de materiales y estructuras.

El nanotubo de carbono es una de las estructuras que hoy por hoy se encuentra establecido como el mayor avance resultante y de mayor aplicabilidad de la nanotecnología. Los nanotubos son 50 a 100 veces más fuertes que el acero y $1 / 6$ de su peso. En determinados materiales con sólo agregar $0,5 \%$ de nanotubos se puede aumentar su resistencia en 20 veces. El nanotubo 
es considerado el gran substituto del silicio, que actualmente se utiliza en la fabricación de componentes electrónicos. El gran obstáculo por el cual hoy por hoy no sé está utilizando el nanotubo masivamente, es porque todavía es difícil conseguir fabricar nanotubos en gran escala para que pueda alimentar la producción industrial. Este tema interesa a muchos empresarios, ya que las pocas empresas que comercializan este producto lo venden aproximadamente a U\$60,00 el gramo. Podemos encontrar en la actualidad aplicaciones de nanotubos principalmente en la Industria aeroespacial, automotriz, construcción y electrónica.

\section{Revolución textil}

La nanotecnología puede ser utilizada dentro de la ingeniería textil en varias áreas para dar a los tejidos diferentes tipos de acabamientos, tales como en los teñidos, para dar suavidad en la superficie, en los colorantes utilizados para hacer los estampados y es por esto que la fabricación de ropas fabricadas con productos nanotecnológicos se denominan inteligentes o textiles nanotecnológicos, como también los calzados o cualquier otro accesorio de moda. Algunos de estos productos poseen algún tipo de fórmula elaborada con nanopartículas que generan algún tipo de reacción. Estas reacciones pueden ser biológicas adentro del organismo o físicas en el propio tejido. Las tintas por este motivo se hacen de combinaciones que puedan ser usadas para la moda, tanto en la utilización de estampados como en los teñidos, y de esta forma es que se denominan prendas nanotecnológicas o como también suelen decir prendas inteligentes, creadas con diferentes procesos tecnológicos que se diferencian una de las otras.

Por ejemplo algunas prendas son hechas con aislamiento térmico para ropas que son utilizadas en actividades físicas como la gimnasia y todo tipo de deportes. Cada tejido recibe una terminación diferente para que el aislamiento térmico sea el necesario para que la prenda cree condiciones que envuelva el cuerpo generando mayor cantidad de calor producido por el cuerpo de acuerdo con la actividad física realizada. De acuerdo con ese calor serán las reacciones biológicas producidas interiormente. Estas prendas especiales no son fabricadas únicamente para ser utilizadas por los deportistas, también son fabricadas para utilizar en lugares donde las temperaturas son bajas, proporcionando confort a las personas.

También existen otros tejidos llamados inteligentes que crean automáticamente aislamiento térmico, necesario entre el tejido de la ropa y el cuerpo de la persona que lo está vistiendo, mudando de esta forma su fase térmica a través de una memoria electrónica. Los principales materiales inteligentes y nanotecnológicos creados para la moda son los llamados de música $T$ - Shirts, vestidos para negocios, camperas de recarga con energía solar y otros. La utilización de la tecnología electrónica utilizadas en todo tipo de vestuario significó una nueva era en toda la industria de la moda.

Comentando otros aspectos tecnológicos creados en la industria textil propiamente utilizados para las terminaciones de superficie, podemos abordar en el más innovador de todos, llamado de nanotecnología, utilizado especialmente para diferentes tipos de tejidos tanto sean estos para la moda de vestuario como para calzados. Estas terminaciones de superficie son altamente activas como por ejemplo las anti UV, o las superficies que son auto-limpiantes con propiedades anti-microbios. Las superficies auto-limpiantes, reciben un tratamiento con un producto cuya fórmula esta hecha a base de $\mathrm{TiO} 2$ / $\mathrm{ZnO} 2$, llamados de Nano revestimientos. Con estos 
Nano revestimientos se podrán incluir en cualquier tipo de superficies sin tener en cuenta el tipo de tejido ni el uso para cual fue fabricado, estos revestimientos llamados de auto-limpiantes se hacen con diferentes cantidades de camadas de nanocompuestos, donde ópticamente las superficies funcionales para revestimientos anti-reflejo de displays, que son llamados también de efectos de ojos de mariposa.

Las nanopartículas de arcilla o también llamados de nanoflakes son compuestos por varios tipos de hidratados aluminosilicatos. Cada uno de estos compuestos son diferentes químicamente en su estructura cristalina. Estas arcillas poseen propiedades de aumento de temperatura eléctrica y resistencia química junto con una capacidad para ser un poderoso bloqueador a los rayos UV. Por lo tanto estas fibras reforzadas con nanopartículas de arcilla tienen comportamientos ignifugas como también anticorrosivos.

Las nanopartículas de terminaciones pueden ser utilizadas individualmente para los lugares designados en materiales textiles con una orientación específica y su trayectoria a través de termodinámica, electrostática u otras formas de abordar técnicamente.

\section{Revestimientos químicos y funciones}

La nanotecnología no solamente ejerció una gran influencia en la creación de fibras versátiles composites, como también fue muy importante para el desarrollo de terminaciones utilizando sustancias químicas revolucionarias. Una de las tendencias del momento es realizar un proceso de sintetización y con la emulsión resultante aplicarla en nanoescala sobre la superficie de los tejidos de una forma profunda y de una forma mucho más precisa y firme, para evitar la pérdida del producto a través de los sucesivos lavados y uso.

Las nanopartículas como el oxido de metal y las cerámicas, también son empleadas en las terminaciones de diferentes tipos de tejidos para alterar las superficies dando algunas funciones a las terminaciones, como por ejemplo los tejidos tratados con nanopartículas de $\mathrm{TiO} 2$ y $\mathrm{MgO}$ substituyen los tejidos con carbón activado, siendo utilizados anteriormente como protectores de diferentes materiales. Las actividades foto catalíticas del $\mathrm{TiO} 2$ y de las nanopartículas de $\mathrm{MgO}$ tienen propiedades que eliminan agentes toxiquímicos y biológicos cuando estos son proyectados para la incorporación en las fibras a través de la mezcla con diferentes substratos textiles. Una de las técnicas para abordar los nuevos revestimientos nanotecnológicos controlados a través de la biología molecular, donde las nanocamadas son de atracción electrostáticas automontadas en las superficies de diferentes tipos de tejidos y cueros.

El proceso de automontaje comienza por la carga en la superficie de poli electrólitos opuestos. La cantidad de material absorbido es auto limitado por la densidad de la carga del substrato, siendo esta una solución de polímeros que elimina el excedente simplemente lavando con una solución neutra. En cada camada se colocan cargas opuestas de poli anión y poli catos, de esta manera el espesor del film es formado de acuerdo con la necesidad de cada producto. Los fundamentos de la electrostática es más compleja para ser fabricada de lo que parece, pero sus resultados traen mayores beneficiosos.

La revolución en hilados High-Tech, empezó en la década de 30 en los EUA con el estudio de las grandes moléculas o de los polímeros. La empresa Du Pont desarrolló la primera fibra sintética, 
el nylon, siendo más resistente que los tejidos naturales y pudiendo ser utilizado con diferentes exigencias. Desde entonces la evolución de las fibras sintéticas podríamos decir que viene a pasos agigantados.

Durante los años 90 con el lanzamiento de la microfibra, el primer tejido inteligente (entendamos por tejido inteligente aquel que es desarrollado y utilizado para suplir alguna exigencia además de la convencional), los tejidos High-Tech empezaron a ser más explorados por la industria textil, no solamente por los beneficios que proporcionan, pero también gracias a la posibilidad de poder mezclar fibras sintéticas con naturales y así posibilitar a la industria textil producir una mayor variedad de piezas de ropa en las más diversas gamas de la indumentaria, como jeans wear, sport wear, casual, work wear entre otras.

La moda, está actuando de filtro y válvula dosificadora entre la industria textil y el consumidor final. No es casual que hasta ahora no tuvimos una invasión en el mercado. Realmente la moda está sabiendo aprovechar los nuevos tejidos y se está encargando de distribuir y organizar para mayor beneficio de la sociedad y con extrema delicadeza lo está introduciendo al consumidor final. Tanta delicadeza que es muy probable que ahora mismo estemos usando alguna pieza de ropa HighTech o nanotecnológica, sin que sepamos realmente todos los beneficios que nos proporcionan. Con la rapidez de la evolución de los tejidos y la sutileza de la moda, se perdió de vista lo que es un tejido Hi-Tech y lo que es un tejido Nanotecnológico pues al final lo que más llama la atención es el beneficio que causa y no como está realmente hecho.

Debemos entender la diferencia entre lo que es un tejido High-Tech, lo que es un tejido con acabado Nanotecnológico y los que es un Nanotejido.

\section{Tejidos High-Tech}

Los tejidos High-Tech e Inteligentes, son los que se encuentran con mayor facilidad o los que están siendo más utilizados en la moda actualmente. Estos se clasifican en tres grupos: Tejido de Alta Prestación, Tejidos de Alta Función y Tejido de Alta Estética. Cada tipo de tejido High-Tech es sintético y por eso puede ser fabricado y diseñado para suplir alguna exigencia además de lo convencional. Sus propiedades son biológicas, químicas o mecánicas y las principales funciones que encontramos son: absorción de agua, repulsión de agua, permeabilidad a la humedad, generación y retención de calor, intercambio iónico, anti-hongos, anti-insectos y perfumado. Jamás podemos decir que un producto es nanotecnológico por sus beneficios y sí por la escala o medida Nano en la que es fabricado. Por eso no podemos llamar estos tejidos nanotecnológicos pues las medidas son en escala Micra y no Nano.

Las fibras nanoestructuradas compuestas, son las que dieron inicio a la era de los nanotejidos. Estas fibras tienen compuestos de nanopartículas tales como arcilla, óxidos metálicos, carbono negro, grafito y nanotubos de carbonos. Además este tipo de nano estructurados, existen otros tipo de fibras compuestas que son producidas a través de procesos de espuma, y otras que usan rellenos de tamaño nanométricos. De esta forma se aumenta la resistencia mecánica y mejoran las propiedades físicas tales como conductividad y comportamientos anti-estáticos.

De esta forma las nanopartículas tienen una mejor interacción con los polímeros y por su gran área de cubrimiento superficial mejora la interacción entre las moléculas. Al encontrarse en 
una escala nanométrica el recubrimiento es mayor e interfiere en los movimientos de la cadena polimérica recibiendo mejor movilidad. Las nanoparticulas poliméricas distribuidas pueden transportar carga, aumentar la resistencia y abrasión.

\section{Tejidos con acabados nanotecnológicos}

Los tejidos con acabados nanotecnológicos recién ahora empiezan a llegar al mercado. Estos tejidos no son solamente sintéticos, sino también vegetales y naturales. Por trabajar en escala Nano es posible incorporar cualquier nanopartícula en las más diversas superficies, manteniendo siempre la misma característica, propiedad, suavidad, brillo y caída. Un ejemplo común seria el algodón. Desde el año 2000 aproximadamente la era nanotecnológica comenzó a sumarse en los laboratorios textiles del mundo y junto con la era High-Tech, consiguieron un mayor avanzo en calidad y beneficios. Podría clasificar en cuatro grupos por beneficios:

Estética: Permite que las piezas puedan resistir a derrames de líquidos sin ser absorbidos, que no se arruguen y sean anti-manchas.

Terapéuticos: Hidratantes, prevención de varices y estrías, tonificador muscular y equilibrador molecular.

Fármacos: Administración de vitaminas y remedios.

Protectores: Bactericida, protector de rayos UVB/UVA, protector de polución y gases nocivos.

Entre los tejidos citados de estética y protectores, los más utilizados comercialmente en la actualidad son los tejidos bactericidas. Estos son fabricados con partículas de nanoplata. La plata posee propiedades antibacterianas naturales y estas propiedades son reforzadas cuando el metal forma partículas muy pequeñas con una medida de 10 a 20 nanómetros cada una. La nanoplata, también disminuye la necesidad de lavar los tejidos con tanta periodicidad, ya que las bacterias son destruidas y al ser tan pequeñas las partículas que ocupan los espacios de las fibras evitan la acumulación de todo tipo de suciedad y manchas. Ya los tejidos que no permiten la penetración de líquidos, consisten en adherir filamentos diminutos a las fibras textiles, utilizando ganchitos nanométricos. Estos filamentos impiden que los líquidos penetren la superficie de la tela.

Por el lado de los Terapéuticos, desde algunos años, existe ropa interior con hidratantes entre sus fibras, dentro de micro cápsulas. Esta nanotecnología permite administrar la hidratación de la piel, liberando el hidratante a medida que la piel lo necesita. Otro producto que recién está llegando al mercado son los jeans tonificadores musculares y equilibradores moleculares. Estos jeans sufren tratamientos con nanopartículas en sus fibras y al recibir calor, las nanopartículas son capaces de generar una energía tan pequeña pero perfecta para activar y equilibrar las moléculas del cuerpo.

Los fármacos en tejidos ya son una realidad, pero todavía hay mucho que estudiar y perfeccionar para que sean comerciables. Los principales problemas encontrados son justamente en la dosificación de los fármacos o vitaminas que el organismo necesita. 
Los tejidos protectores pueden y deberán ser los más utilizados por la sociedad ya que cada día que pasa la polución y los rayos solares dañan más y más al ser humano. En el tejido protector de polución, actúa la partícula de Paladio, esta es menor todavía y por ser uno de los mejores catalizadores que existen, son capaces de oxidar los gases presentes donde existe polución. Uno de los mayores beneficios que se puede encontrar en este tipo de tejido, es para las personas alérgicas, porque estarán menos expuestas a todos los gases tóxicos principalmente en las grandes ciudades. Las ropas con protección de rayos UVA/UVB protegen como si fuesen un factor 50 y garante $98 \%$ de protección contra los rayos solares. Los hilos de estas ropas son hechos de dióxido de titanio especialmente para proteger.

\section{Nanotejidos}

Cuando hablamos de "Tejidos", generalmente lo primero que nos viene a la cabeza es algo hecho con diferentes tipos de hilos, los cuales le dan la característica al tejido y que sé usan de diferentes maneras para diferentes cosas. En realidad no estamos equivocados, pero lo que pensamos fue en una tela. Al buscar la palabra "Tejido" en el diccionario de la Real Academia Española encontramos varios resultados, los cuales la gran mayoría hacen mención al tejido celular. Ahora cuando nos referimos a "Nanotejido", también pensamos en telas pero la cosa cambia un poco, lo que más encontramos por los laboratorios son tejidos formados por diversos elementos o diversas nanofibras.

El principal Nanotejido descubierto es para la medicina. Los nanotejidos son fabricados con nanofibras de polímeros, de dimensiones entre 20 y 30 nanómetros el cual equivale entre 200 y 500 veces menor que un hilo de cabello. Estos nuevos nanotejidos tienen potencial para servir como materia prima para la fabricación de tejidos biológicos, tejidos para implantes y para la fabricación de órganos artificiales humanos. Inclusive ya sé habla de nanotejidos de proteínas que el mismo tejido natural usa, o sea se haría un nanotejido 100\% natural.

El grupo de la Universidad de Texas desarrolló una tela a base de nanotubos de carbono que es 17 veces más resistente que el kevlar (actualmente usado para fabricar los chalecos antibalas) y que puede conducir carga eléctrica, lo que permite activar equipos electrónicos, como teléfonos celulares, etc. El usuario puede generar electricidad mientras se mueve, sin embargo es claro, que dependiendo del valor de la corriente eléctrica que pase por un cuerpo humano, siempre causa algún efecto directo en la salud.

Como nanotextiles, se han desarrolado nanofibras de polímeros que pueden ser estirados hasta un $1.500 \%$, en cuanto los hilos sintéticos normales solo pueden ser estirados hasta un $600 \%$. La técnica de fabricación de las nanofibras para la industria textil es muy simple y podrán ser fabricadas en cualquier laboratorio.

\section{Electrohilo}

Hoy el método más usado para la fabricación de nanofibras, consiste en conducir una alta tensión eléctrica en forma de gotas de polímeros líquidos para crear filamentos en nanoescala. Las nanofibras son formadas en el interior de una centrífuga, al poner polímeros se estiran 
como si fuera el azúcar cuando se derrite y al secarse, esta formado por finísimos hilos muy parecidos al de la seda natural. Las nanofibras son extrusadas a través de varias salidas en una combinación de presión hidrostática y centrifugado.

Por este motivo las nanofibras son formadas todas de las mismas medidas. Esta técnica posibilita obtener un alto grado de flexibilidad en la producción ya que el diámetro de los hilos puede ser fácilmente manipulado.

A pesar de la eficacia de las nanofibras, no permite el control sobre el proceso de la fabricación, además de la producción ser baja para fabricarlos de forma industrial.

\section{Medicina}

Las investigaciones más avanzadas se registran en el campo de la medicina y la biología. Según datos de Lux Research, a nivel mundial el mercado de la nanotecnología movía ya en 200611.800 millones de dólares en esfuerzo investigador y 50.000 millones de dólares en productos que incorporan nanotecnologías, cifra que está previsto que alcance los 2,9 billones de dólares en 2014.

\section{Cáncer}

Entre la medicina y la nanotecnología están formando un arma para combatir el cáncer. Al combatir la enfermedad en escala molecular, permite detectar precozmente la enfermedad, identificar y atacar más específicamente a las células cancerígenas. El Instituto Nacional del Cáncer de Estados Unidos (NCI) ha puesto en marcha la "Alianza para la nanotecnología en el cáncer", un proyecto que incluye el desarrollo y creación de instrumentos para la detección precoz.

Una de las alternativas es administrar y direccionar medicamentos. Esta nueva técnica ya es un hecho. Los nanosistemas de liberación de fármacos actúan como transportadores de fármacos a través del organismo, direccionado a las células tumorales y reduciendo el acumulo de fármacos en las células sanas.

Los sistemas de liberación de fármacos están constituidos por un principio activo y un sistema transportador, los cuales garantizan que se pueda dirigir la liberación del fármaco al lugar que lo necesite y en la cantidad adecuada. Estos deben cumplir con ciertas características, como lo son la baja toxicidad, propiedades óptimas para el transporte, liberación del fármaco y un alarga vida media en el organismo. Todas estas características son favorecidas por la aplicación de la nanotecnología en este campo. Todo esto permite que, por medio de la fabricación de dispositivos a escala nanométrica, se libere el fármaco de la forma menos invasiva y toxica para el tejido celular que no necesite del tratamiento farmacológico. Otra ventaja que ofrece la nanotecnología a la liberación de fármacos es el evidente aumento de la efectividad del medicamento, por medio del control preciso de la dosis requerida, del tamaño, la morfología y las propiedades superficiales del compuesto farmacológico a utilizar. Al liberarse nanopartículas de forma específica sólo en órganos, tejidos o células que lo necesiten, se disminuye la toxicidad asociada al fármaco. Por otra parte, en necesario tener en cuenta que los sistemas de administración de fármacos permiten la liberación sostenida del medicamento de acuerdo con las necesidades del paciente; lo que permite la disminución de posibles efectos adversos que se puedan presentar 
como consecuencia de la administración masiva y prolongada de un fármaco determinado. Otra alternativa está basada en unas moléculas artificiales conocidas como dendrímeros. Se trata de estructuras tridimensionales ramificadas que pueden diseñarse a escala nanométrica. Los dendrímeros cuentan con varios extremos libres, en los que se pueden acoplar y ser transportadas moléculas de distinta naturaleza, desde agentes terapéuticos hasta moléculas fluorescentes. En los Estados Unidos, el nanotecnológo James Baker, aplicó un poderoso medicamento contra el cáncer, metotrexato, a algunas ramas del dendrímero. En otras, incorporó agentes fluorescentes, así como ácido fólico o folato, una vitamina necesaria para el funcionamiento celular. Su funcionalidad es como la de un caballo de Troya. Las moléculas del folato en el dendrímero se aferran a los receptores de las membranas celulares y éstas piensan que están recibiendo la vitamina. Cuando permiten que el folato traspase la membrana, la célula también recibe el fármaco que la envenena.

\section{Nanosistemas de diagnóstico}

No son solamente las terapias que están avanzando en la nanotecnología, el diagnóstico no se queda atrás. De la mano de la nanotecnología nos encontramos con la era del diagnóstico molecular y cuántico, estos son sofisticados y precisos, que hacen posibles identificar enfermedades genéticas e infecciosas. Entre los tipos de diagnósticos tenemos los Puntos Cuánticos y los Nanoshells.

El objetivo de los nanosistemas es el identificar la aparición de una enfermedad precisa en los primeros estados a nivel celular o molecular, mediante la utilización de nanopartículas o nanodispositivos. Los nanosistemas de diagnóstico se pueden aplicar in-vitro o in-vivo.

En aplicaciones de diagnóstico in-vitro, los nanodispositivos son capaces de detectar con sorprendente rapidez, precisión y sensibilidad la presencia de microorganismos patógenos, proliferaciones celulares precancerosas y defectos en el ADN a partir de muestras de fluidos corporales o de tejidos.

En aplicaciones de diagnóstico in-vivo, se pueden desarrollar nanodispositivos biocompatibles que, por ejemplo, al ser administrado en el cuerpo humano pueden efectuar unas búsquedas selectivas para identificar una enfermedad y cuantificar la presencia de una determinada molécula o de células cancerígenas.

\section{Puntos cuánticos}

Partiendo de la presunción que todo en la escala biológica es nanotecnología, se están desarrollando una serie de aplicaciones nano con uso médico, este tipo de aplicaciones se están destinando básicamente a diferentes procedimientos para llegar a diagnostico más precisos y rápidos con la utilización de puntos cuánticos o mas conocidos también como Quantum Dots. Los puntos cuánticos consisten en dispositivos de baja dimensión y su tamaño nanométrico provoca un efecto de confinamiento en su estructura. Son fabricados por nano cristales semiconductores naloleds y contienen sólo unos cientos de átomos. Cuando son excitados emiten luz en diferentes longitudes de onda dependiendo de su tamaño, por lo que son extremada- 
mente útiles como marcadores biológicos de la actividad celular. Para llegar a este grado de funcionalidad, los puntos cuánticos requieren de una protección externa (shell) que evita que el núcleo sufra una disolución espontánea.Como ejemplo podemos decir que esta aplicación es utilizada en identificar bacterias infecciosas. Para ello bastaría conectar algunos puntos cuánticos en anticuerpos y usar las propiedades luminosas de los puntos, para observar como ellos reaccionan). Todos estos nuevos procedimientos que están siendo utilizados con nanotecnología son denominados de medicina cuántica.

\section{Nanoshells}

Nanoshells. Son nanopartículas que se conforman por una delgada capa metálica generalmente de oro, de unos 8 a 10 nanómetros que recubre una estructura esférica de silicio de un diámetro aproximado de unos 100 nanómetros. Los nanoshells poseen la capacidad de absorber o reflejar rayos de luz a la longitud de onda deseada, lo que les confiere una propiedad de luminiscencia reactiva, que en determinado momento si la fuente de luz persiste durante cierto tiempo, induciría a los nanoshells a incrementar su temperatura hasta valores suficientes como para "destruir" células enfermas o generar procesos acelerados de escarificación o reconstrucción. Como consecuencia, las nanopartículas nanoshell, ofrecen una plataforma tecnológica para una amplia variedad de terapias diagnósticas, todas ellas sujetas a la posibilidad de ligar a la superficie metálica de una nanoshell, moléculas receptoras especificas a una sustancia u organismo prepatógeno en particular.

Las propiedades de las nanoshells son aplicables en la localización, reconocimiento y destrucción termal de células cancerígenas específicas y de angiogénesis particulares en la proliferación tumoral, utilizando un láser infrarrojo que penetra los tejidos y sangre sin dificultad para generar la reacción deseada en las nanopartículas.

\section{Agricultura}

La selección y mejoramiento de las especies de plantas, hasta hace algunas décadas estuvo a cargo de la naturaleza. La irrupción de la industria agrícola biotecnológica en el sector agrícola, cambió el objetivo de tal selección, ya no hacía a la supervivencia y aprovechamiento de tal especie, resultado de la selección natural, si no que introduce como fin el mejorar y maximizar la producción de los procesos agrícolas.

Para conseguir tal objetivo, una de las opciones que primero emergió fue el desarrollo de herbicidas, la biotecnología agrícola estructuró la opción de producir químicos que respondieran a las necesidades de las plantas. Diseñando plantas que pudieran tolerar químicos tóxicos o se "defendieran" de las plagas que tantos daños causan al sector económico.

En el ámbito agrícola, la producción en el mundo históricamente ha sido facilitada por las más diversas tecnologías de producción. Uno de los principales factores por el aumento de producción y disminución de costos, es el aprovechamiento máximo y selección especial de las "mejores" semillas, desarrolladas tecnológica y genéticamente. 
Por medio de la nanobiotecnología ya se plantea la posibilidad de diseñar la planta a través de la manipulación de las semillas. Las investigaciones en este campo se basan en el desarrollo de nuevas técnicas que utilizan nano partículas que les permiten introducir ADN ajeno a una célula. Por ejemplo, los investigadores del laboratorio Oak Ridge, descubrieron una técnica de escala nanométrica para simultáneamente inyectar ADN a millones de células. Se ha logrado que millones de nano fibras de carbono con ADN sintético adheridas, crezcan de un chip de silicio. Se lanzan entonces las células vivas contra las fibras que las perforan y les inyectan ADN en el proceso. Una vez inyectado el ADN sintético, éste expresa nuevas proteínas y nuevos rasgos que en la actualidad no están siendo investigados.

Plaguicidas nanométricos: venenos encapsulados. En la actualidad la industria de los plaguicidas están iniciando su incursión hacia la utilización de ingredientes activos nanometritos y muchas de las principales firmas agro químicas del mundo llevan a cabo investigación y desarrollo para arribar a nuevas fórmulas de nano escala en la producción de pesticidas.

\section{Medio ambiente}

El medio ambiente como uno de los macro determinantes de la salud y la vida humana también sufre en la actualidad el impacto que tiene la aplicación de la nanotecnología. Surge como uno de los principales temas de interés en el cuidado de la salud humana en el universo nanológico, la principal incertidumbre se genera sobre la capacidad que tiene la materia y los materiales de adquirir propiedades nuevas. Las posibilidades de poder haber cambios a escala nanométrica en la elasticidad, la fuerza y el color de una sustancia, su tolerancia a la temperatura, la presión y su capacidad para conducir electricidad generan interrogantes profundos acerca de lo perjudicial que puede traer la sustancia nanométricas para el medio ambiente.

Cada vez más las nanopartículas se vuelven "funcionales", en el sentido de que sus superficies se acondicionan para desencadenar reacciones químicas o biológicas específicas. De esta manera se crean mecanismos para la administración de medicamentos a seres humanos y animales con fines específicos o para el tratamiento de los cultivos con plaguicidas y fertilizantes. Su administración con fines específicos facilita el uso más eficaz de las sustancias en cantidades muy inferiores, ya que existe la posibilidad de reducir el uso de productos químicos y materiales, en particular los que perjudican al medio ambiente.

Los adelantos en la nanotecnología pueden beneficiar al medio ambiente mediante la utilización de dispositivos de detección que sean menos costosos y más sensibles que los actuales. Por ejemplo los nuevos sensores nanotecnológicos basados en proteínas, pueden detectar el mercurio en concentraciones de aproximadamente una parte en 10-15 o una cuadrillonésima. Lo que antes resultaba en una tarea imposible. Con nanopartículas de óxido de europio se está aplicando un método sumamente sensible para medir el plaguicida atracina, un contaminante que se encuentra con frecuencia en las aguas subterráneas.

La rápida detección gracias a la nanotecnología permite una rápida respuesta, lo que minimiza los daños sobre el medio ambiente y sobre quienes nos beneficiamos de él, también reduce los costos de eliminación de la contaminación.

Algunos materiales nanoestructurados podrían purificar el agua corriente y el agua subterrá- 
nea, esta es una realidad, ya que se dispone comercialmente de membranas nanoporosas que filtran los agentes patógenos y otros materiales indeseables. Algunos científicos proponen el uso de nanopartículas de hierro como reductor químico para descontaminar el agua. En este proceso, el hierro, sustancia que existe en la naturaleza, oxida y se oxida; aprovechando la gran superficie de las nanopartículas. Los nanocristales de hierro magnetizado se utilizan para eliminar el arsénico del agua potable. Existen informes que apuntan a que este método reduce en más de cien veces, la cantidad de desechos producidos por las técnicas estándar. Otro método innovador supone la impregnación de la superficie de las partículas de óxido de hierro con moléculas que selectivamente crean enlaces con moléculas o iones contaminantes. $\mathrm{Al}$ introducirlas en el agua resultaría en la atracción del contaminante por parte de las partículas impregnadas y por medio de un campo magnético se concentran captando los pares atrapados.

Hoy en día existen muchas otras investigaciones y aplicaciones que establecen la nanotecnología como un medio para limpiar el medioambiente contaminado, lo que contribuiría a una interacción mas "sana" del ser humano con el medio ambiente, donde el medio ambiente no se vea afectado por las acciones industriales y tecnológicas que el ser humano realiza, favoreciéndose de la interacción con los recursos naturales en busca de un beneficio y bienestar propios. Varias tecnologías, entre ellas los catalizadores nanoestructurados para pilas de combustible y los materiales perfeccionados de los electrodos en acumuladores de iones de litio y las pilas fotovoltaicas avanzadas de silicona nanoporosa y $\mathrm{TiO} 2$, pueden aumentar el rendimiento de las actuales fuentes de energía y reducir las emisiones de dióxido de carbono (CO2). Los revestimientos a nanoescala ópticamente selectivos pueden reducir el consumo de energía y al mismo tiempo mejorar la calidad del aire en interiores.

Son importantes las posibilidades de ahorrar recursos que ofrece la nanotecnología; en la etapa de producción permite reducir el uso de materiales que dejan una gran "huella en el medio ambiente" sustituyéndolos por otros de menor impacto, como por ejemplo la sustitución del silicio, que actualmente se utiliza para la fabricación de componentes electrónicos, por el nanotubo. Con esto lo que se promueve es un uso más eficaz de las materias primas, lo que ofrece como fin último la conservación del medioambiente, quien es el principal proveedor.

Las investigaciones actuales apuntan hacia la producción de materiales nanoestructurados a partir de fuentes renovables o abundantes (por ejemplo, la sustitución de metales preciosos por nanoproductos a base de carbono). Las estrategias dinámicas de recuperación o reciclado de nanomateriales serían la forma más efectiva planteada para la sostenibilidad de los recursos naturales. Los organismos públicos y privados no han tardado en reconocer los evidentes beneficios de la nanotecnología para el medio ambiente, aunque hacen falta calcular los costos totales de este moderno sector, entre ellos, los costos del ciclo de vida de los productos. Por ejemplo, muchos materiales nanoestructurados ahorran energía durante su utilización, pero su manufactura puede consumir mucha energía. Los análisis de beneficios en función de los costos deben tener en cuenta el verdadero impacto ambiental de estos materiales, además se deben investigar en todos sus aspectos el destino y el transporte de las nanopartículas que se escapan al medio ambiente y tienen sus repercusiones con todo ente biológico que esté en interacción. 


\section{Los riesgos en el medio ambiente}

Las nuevas tecnologías (en su gran mayoría) se producen y aplican sin pasar por una investigación que exponga los posibles efectos a corto y largo plazo de dicha tecnología sobre el medio ambiente. La nanotecnología no es caso exento, éstas pueden presentar riesgos potenciales específicos, los cuales exigen un minucioso estudio y evaluación. Uno de los elementos que demuestra el riesgo de la materia manipulada a escala nano, es que aunque la cantidad de materia utilizada para un proceso nanológico sea mínima, el tamaño de las partículas sigue siendo mucho menor, lo suficiente como para penetrar la piel.

Estas partículas en contacto con el medio que le rodea lograrían tener infinidad de reacciones dependiendo la nanopartículas, el medio (agua, aire, suelo), y las condiciones (temperatura, frío, otras nanopartículas etc.). Esas nanopartículas en dichos medios y condiciones, hoy por hoy son la preocupación y el objeto de estudio en la investigación del impacto que podría resultar de la interacción de las nanopartículas con el medio ambiente y con el ser humano.

\section{Economía}

Bastaría decir para despertar el interés de muchos industriales, inversionistas, emprendedores y gobernantes para la nanotecnología, que se estima que las ventas anuales globales relacionadas con la nanotecnología proyectan para el año 2015, por encima del orden de los US\$2,6 trillones de dólares anuales y cuyos mercados, según Lux Research Inc. representarían aproximadamente 15\% de la producción lucrativa en casi todos los sectores de las economías industriales a nivel mundial y cerca de 10 millones de puestos de trabajo en todo el mundo, sino mas.

Como una gran empresa que está dividida en departamentos, los cuales tienen una función determinante, la Argentina debe organizarse para conseguir una evolución vertical sin detenerse en burocracias y obstáculos innecesarios, debe utilizar la gran cantidad y calidad de científicos que tiene que estadísticamente estamos hablando de 2 científicos cada 1.000 habitantes económicamente activos que es una de las densidades más importantes de America Latina. Debemos saber claramente que el mundo no nos espera, sigue desarrollándose sin detenerse y si no queremos distanciarnos mas todavía de las principales economías, debemos apretar el paso y hacer las cosas bien.

Los principales puntos que debemos observar para conseguir una transición adecuada serían:

- Promover la nanotecnología en todo el sistema educacional y productivo público y privado.

- Promover créditos y financiamientos públicos y privados, para el desarrollo de proyectos de investigación, incubadoras tecnológicas, PyMES y grandes empresas.

- Adecuar el sistema jurídico y legislativo.

- Incentivos fiscales para el estimulo emprendedor.

- Crear un sistema adecuado para depósito de patentes. 


\section{El primer paso}

El primer paso argentino hacia la nueva era de la nanotecnología fue en el año de 2005, cuando se creó por el Decreto 380/2005 del Poder Ejecutivo Nacional, La Fundación Argentina de Nanotecnología - FAN. Esta una entidad de derecho privado y sin fines de lucro, tiene por objetivo el fomento y promoción del desarrollo de la infraestructura humana y técnica del país en el campo de la nanotecnología y microtecnología.

También en el mes de noviembre de 2005 Argentina y Brasil, crearon el Centro Argentino- Brasileño de Nanociencia y Nanotecnología (CABNN). Este se encarga de promover reuniones, workshops, cursos, escuelas entre ambos países para el intercambio intelectual y tecnológico.

\section{Sistema científico argentino de nanotecnología}

El sistema científico argentino de nanotecnología está compuesto por cuatro redes de actividad, que reúnen aproximadamente 250 científicos. En la rama de Física y Materiales las instituciones dedicadas son, Centro Atómico Bariloche - CAB y Comisión Nacional de Energía Atómica (CNEA), que están controlados por la Red de Sistemas Microelectromecánicos (MMES). Para la Química y Materiales está el Instituto de Investigaciones Fisicoquímicas Teóricas y Aplicadas (INIFTA) de la Universidad de La Plata. En el campo de la Biología están La Universidad Nacional de Córdoba y el Centro de Investigaciones en Química Biológica de Córdoba.

Además está el Centro Interdisciplinario de Nanociencia y Nanotecnología, del cual participan el INIFTA, el Consejo Nacional de Investigaciones Científicas (CONICET), la Comisión Nacional de Energía Atómica, junto con el Centro Atómico Bariloche, el Centro Atómico Constituyentes y el Instituto de Química Física de los Materiales Medio Ambiente y Energía, de la Facultad de Ciencias Exactas y Naturales de la Universidad de Buenos Aires, que cuentan con un equipo de 80 científicos e integrantes de las redes mencionadas.

Cabe destacar, también la actuación del Instituto Nacional de Tecnología Industrial (INTI), que cuenta con grupos de investigación y desarrollo (I\&D) en las áreas de electrónica e informática, metrología, mecánica y química, y del Instituto Nacional de Tecnología Agropecuaria (INTA), que se dedica a desarrollar materiales nanoestructurados para aplicaciones industriales con finalidad de usos espaciales o en áreas relacionadas à seguridad del medio ambiente, diagnóstico médico e industria farmacéutica.

La aplicación de la nanotecnología en el sector productivo está siendo conducida por la "Fundación Argentina de Nanotecnología" (FAN), encargada de articular la colaboración entre organismos públicos, empresas y organizaciones del área de ciencia, tecnología e innovación. La FAN está subordinada, desde 2007, al "Ministerio de Ciencia, Tecnología e Innovación Productiva" (MINCyT).

\section{Divulgando la nanotecnología}

El interés por parte de los industriales, inversionistas y emprendedores no es menor, ya que cada uno de estos participantes del mercado tienen papeles sumamente importantes para la 
evolución de la nanotecnología en la Argentina.

Los industriales, son los principales responsables por la demanda de tecnologías de producción. La necesidad de la divulgación entre los industriales, inversionistas y emprendedores del país sobre el conocimiento y las posibilidades que trae la nanotecnología, es tan o más importante que entre los docentes y estudiantes, pues son ellos que dictarán el rumbo de los estudios y aplicaciones de la nanotecnología y que presionarán al sistema para un avance normativo y jurídico. Es imprescindible la homogeneización entre los empresarios y los científicos, a través de ferias, workshops, seminarios etc. Estos medios de divulgación serán sumamente importantes para la concientización del industrial, para el surgimiento de la cooperación entre la industria y el laboratorio, las inversiones privadas en proyectos nanotecnológicos y el desarrollo como un todo en las cadenas de investigación y producción. Lo que tal vez se debería hacer es un acuerdo entre las pequeñas y medianas empresas en general con los institutos de investigación para la colaboración científica. Todo lo que sea hecho hoy en este sentido para avanzar en la nanotecnología sin lugar a dudas, será una gran contribución para el futuro económico y social en la salud, medicina, nutrición, agricultura entre otros.

Por dar un ejemplo, la Argentina es el octavo país del mundo en términos de superficie y uno de los principales territorios con tierras de excelencia para la producción agrícola y ganadera que representa uno de los pilares de la actividad económica. Con cifras de la Secretaría de Agricultura, de Cámaras sectoriales y el asesoramiento de profesionales de la Facultad de Agronomía de la UBA, se estima que para 2011 se producirán 135 millones de toneladas de granos, cantidad suficiente para alimentar a 450 millones de personas. La Argentina podría concentrar esfuerzos de investigación y desarrollo recurriendo a aplicaciones de nanotecnología en alimentos, por ejemplo en envases inteligentes que agreguen valor a nuestros comestibles, o nanotecnologías para aumentar la producción y disminuir el impacto ambiental causado por los desechos tóxicos, entre tantas otras posibilidades.

\section{Créditos}

En el año de 2007, La Fundación Argentina de Nanotecnología - FAN, realizó una convocatoria donde se presentaron 20 empresas que tenían proyectos o productos con una base de nanotecnología. Entre esos 20 que se presentaron, solamente 3 se financiaron, pues el financiamiento era para proyectos ya avanzados, lo que indica que los otros proyectos estarían recién comenzando. ¿Que pasó con los otros 17 proyectos?, ¿Será que quedaron en algún cajón abandonado?, ¿Será que buscaron créditos en otros países?

Existen empresas, proyectos de estudiantes universitarios, emprendedores aliados con científicos, industrias buscando la excelencia tecnológica, entre tantos otros, listos para desarrollar nuevos productos, abrir nuevas empresas, generar nuevos avances tecnológicos para el país y solamente dependen de recursos financieros para poder dar los primeros pasos, de apoyo del gobierno en sus necesidades, que no siempre son apoyos financieros pero muchas veces las necesidades son de un sistema apto a recibir y entender lo que están haciendo.

Podemos citar 3 como los principales créditos: Crédito no reintegrable, Crédito de Financiación y Joint Venture.

Los créditos no reintegrables son primordiales más que fundamentales para las primeras eta- 
pas de los proyectos. Estos aportes son casi del 100\% los otorga el gobierno como incentivo al desarrollo del país. Estos créditos son los que proporcionan a los pequeños empresarios y emprendedores dar los primeros pasos. Estos posibilitan crear un laboratorio de investigación en la empresa, contratar Doctores, asesorías empresariales, viajes a las principales ferias de nanotecnología en Europa, Estados Unidos y Japón, adquisición de tecnologías, entre tantas otras necesidades para empezar a producir.

El Plano Estratégico Nacional Bicentenario (2006-2010) establece como meta de inversión pública para el sector de ciencia y tecnología 1\% del PIB. De acuerdo con el proyecto 2010 del MINCyT. Por ahora, el montante destinado al sector equivale, efectivamente, a 0,42\% do PIB.

El Ministerio de Ciencia, Tecnología e Innovación Productiva de Argentina (MINCyT) anunció el día 14 de mayo de 2010, la apertura del Fondo Sectorial de Nanotecnología, con el fin de impulsar la investigación, desarrollo e innovación en esta área. La convocatoria, administrada a través del Fondo Argentino Sectorial de la Agencia Nacional de Promoción Científica y Tecnológica, otorgará aportes no reintegrables de hasta $\$ 30.400 .000$ (alrededor de US $\$ 7.800 .000$ ) por proyecto. Es sumamente importante destacar que estos fondos públicos son los que demuestran a los fondos privados la solidez en apoyar proyectos de nanotecnología y que los Créditos de financiación privados pueden ser muy rentables a medio y largo plazo para los bancos.

Las Joint Venture, son otra manera muy importante más para el desarrollo de la nanotecnología junto con el crecimiento de PYMES listas para entrar en el mercado. En castellano, joint venture significa, literalmente, "aventura en conjunto". Joint venture es un tipo de acuerdo comercial de inversión conjunta a largo plazo entre dos o más personas (normalmente personas jurídicas). El aporte puede consistir en materia prima, capital, tecnología, conocimiento del mercado, ventas y canales de distribución, personal, financiamiento o productos, o, lo que es lo mismo: capital, recursos o el simple know-how.

\section{Inversiones en el mundo}

Para tener una idea de cómo avanza el mundo en la nanotecnología y en la nanociencia, veremos algunos números relacionados a la inversión en las principales regiones del mundo.

Según el National Nanotechnology Institute, entre 2003 y el 2009 las inversiones públicas y privadas de los EUA en nanotecnología crecieron un 18\% anual, lo que seria de U\$ 2 billones en 2003 para U\$ 6,4 billones en 2009. Hasta entonces EUA lidera el desarrollo nanotecnológico en todos los sentidos, financiamiento del gobierno, el gasto de las empresas, la inversión de capital de riesgo.

Luego viene la UE con aproximadamente U\$ 3 billones, sin contar las inversiones de cada país individualmente. La comisión Europea propuso a la decisión del Parlamento Europeo y El Consejo Europeo la atribución de 4,83 mil millones de euros al tema de las "Nanociencias, Nanotecnologías, Materiales y nuevas Tecnologías de Producción" (un presupuesto total de 72,73 mil millones de euros).

Rusia no pretende quedarse atrás de ningún país y ya planea invertir cerca de U\$ 10 billones en programas de desarrollo de la nanotecnología hasta el año de 2013. Actualmente Rusia invierte aproximadamente U\$ 1 billón anual.

El artículo intitulado "Ranking de las Naciones sobre Nanotech: Puertos secretos y falsas ame- 
nazas", compara la innovación nanotecnología y desarrollo de tecnologías en 19 países, con la intención de informar a los políticos de los gobiernos, líderes empresariales y inversores, un mapa detallado de la nanotecnología y del desarrollo del escenario internacional. Globalmente el artículo encontró la inversión global manteniéndose constante después de la reciente crisis financiera. Mostró U\$ 17,6 billones de dólares americanos de los gobiernos, corporaciones y inversionistas en 2009, lo que corresponde al aumento en 1\% comparativamente con 2008.

\section{Casos exitosos en la Argentina}

Es sumamente importante mostrar algunos casos exitosos en la Argentina de empresas que creyeron e invirtieron en la nanotecnología y hoy están produciendo y comercializando productos de la más alta tecnología en el mundo.

Una empresa que ya está en el mercado desde 1971 es Darmex. Esta fábrica de productos químicos, tiene como principales clientes a las productoras de neumáticos. Hoy, abastecen a más de 30 países distribuidos en todo el mundo. Teniendo en cuenta la importancia de aplicar recursos en el campo de la investigación y desarrollo, Darmex decidió constituir en la misma organización un Instituto de Investigaciones Científicas, con recursos propios. En el marco de esta iniciativa estratégica, se encuentran trabajando varios equipos de profesionales y técnicos, dentro de los que se destacan los abocados a nanotecnología y simulación numérica. Los desarrollos están orientados a provocar innovaciones en distintos productos, a través de investigaciones micro-nano emulsiones y nano-cargas para polímeros y elastómeros, con el propósito de lograr mejorar la performance del producto.

Nanotek es una firma santafesina con apenas ocho empleados, y se dedica a desarrollar tecnologías para la destrucción de contaminantes de alta resistencia a los tratamientos físicos y biológicos convencionales. Su primer producto patentado fue el nanohierro (nanofe) que se utiliza como catalizador en el tratamiento químico de efluentes industriales y cursos de aguas contaminadas, metales pesados como arsénico, cianuro, plomo, mercurio y la destrucción del PCB (bifenilos policlorados, altamente cancerígenos, que se encuentran en el aceite de ciertos transformadores eléctricos). La compañía también tiene aplicaciones para la minería (remediación de sitios contaminados por derrames producidos durante el manipuleo o transporte de hidrocarburos); y para las plantas de tratamiento de efluentes cloacales. Nanotek, que posee una planta bi-reactor de baja presión con atmósfera controlada y una capacidad instalada de una tonelada mensual de nanometales, ha iniciado en el año de 2007 el desarrollo comercial de NanArgen, una nanopartícula de plata con función funguicida-antibacterial.

\section{Una buena teoría a ser aplicada}

La plata es la substancia más citada como componente de productos nanotecnológicos en venta en el mundo. Una nanopartícula que está comenzando a ser utilizado en tejidos, plásticos, superficies es la Nanopartícula de Plata desarrollada a través de la Plata.

El principal foco de la nanotecnología de una forma inmediata, sería promover y proveer a todos los centros de salud públicos y privados, un nanomaterial para disminuir los focos de cultivos 
infecciosos y toxicológicos o sea un bactericida desarrollado a nivel molecular, esta sofisticada tecnología remueve el $99.9 \%$ de dos microorganismos que son perjudiciales para la salud, el Staphylococcus y la Escherichia colí. Aplicando este nanoproducto en tejidos, muebles, materiales y hasta en la estructura de los hospitales, alcanzaremos una gran evolución y conseguiremos diminuir drásticamente los números que son alarmantes. Según el RID - Comittee Reduce Infection Deaths en los EUA, el número de muertos es por lo menos 103 mil vidas al año. Así se suma el coste económico a la salud pública en más de U\$ 30 billones al año. En la Argentina el número de muertes por infecciones es de 100 mil vidas según ADECI - Asociación Argentina de Enfermeros en Control de Infecciones y el costo al erario público, es del 30\% del total de \$ 45.000 millones para la salud pública o sea más de \$13.500 millones de pesos gastos en remediar, cuando deberían ser gastos en nuevos hospitales, equipamientos, profesionales etc.

\section{Patentes}

La Argentina es el tercer país de América latina en cuanto a las patentes de productos con nanotecnología (12). Primero viene Brasil (89) y luego México (28). Hay que incorporar urgentemente en la discusión el tema legal, en particular sobre las cuestiones regulatorias y de propiedad intelectual, que son imprescindibles para el desarrollo de la actividad industrial y nuevos negocios. En la Argentina no hay una ley que regule tal actividad y el sistema de patentes de productos y soluciones, es para investigadores y empresarios, un trámite demasiado engorroso, que puede tardar hasta 9 años. Lo que desalienta la inversión y la comercialización en el país. Algunas medidas adoptadas para dar solución a esta problemática han sido, entre otras, la creación de clases específicas para patentes nanotecnológicas y la continua capacitación y especialización de examinadores, algunos de ellos incluso nucleados en grupos de trabajo específicos. De cualquier manera para un país que tiene intención en destacarse en la Nanotecnología como mucho debería tardar entre dos (2) a tres (3) años.

Se han registrado a través de publicaciones en el Instituto Nacional de la Propiedad Industrial (INPI), aproximadamente 50 patentes relacionadas con nanotecnología entre mayo de 2007 y marzo de 2009. El $80 \%$ de las 50 patentes presentadas fueron realizadas por empresas, mientras que el $20 \%$ restante se reparte entre universidades y organismo de ciencia y tecnología.

En cuanto a la nacionalidad de los solicitantes, EEUU lidera con el 35\% de las solicitudes, Argentina en segundo con $9 \%$ y el restante fue realizada principalmente por países europeos. Por especificación de nanotecnología, hay cuatro (4) patentes depositadas en nanomateriales, cuatro (4) en nanoherramientas y cuatro (4) en nanoproductos.

\section{Sistema jurídico}

Las posibilidades de reglamentación aunque bajo un panorama difícil, incluyen el "principio de precaución" y la adopción del enfoque del "desarrollo sostenible", desde el punto de vista del riesgo, para ello es necesario considerar dos factores esenciales a incluir dentro de las políticas emergentes: "la probabilidad de que un evento se produzca y el tipo o importancia de los daños resultantes”. Tratándose de tecnologías nanoescalares, estos dos factores no están siem- 
pre presentes dentro de las regulaciones, y normas internacionales, las cuales deben responder al imprescindible cuestionamiento sobre la manera de tratar la incertidumbre científica, con respecto a los conocimientos en el campo de las tecnologías nanoescalares, así como lo que pudiera llegar a suceder al implantarse estas nuevas tecnologías dentro de nuestras sociedades. En principio resumimos en proteger el medio ambiente pero hoy se extiende a contextos más amplios inmersos en los macro determinantes de la vida humana, y que debe incluirse en los esfuerzos normativos insistiendo en que es un principio de acción y no de abstención es decir que antes que limitar el desarrollo tecnológico, y que puede guiar a las autoridades en un contexto de incertidumbre. La gestión de riesgos hipotéticos en una sociedad pluralista y democrática, en particular sobre la brecha existente entre la aceptabilidad del riesgo individual y del riesgo colectivo, entre las exigencias de seguridad sanitaria y ambiental y la aspiración legítima del desarrollo tecnológico.

En todo el mundo, existe un determinado número de leyes, normas y reglamentos que regulan el ciclo de vida de un producto, desde su fabricación hasta su eliminación. Estos textos legislativos que abarcan desde tratados de libre comercio hasta regulaciones locales a los procesos de producción y mercadeo, se aplican igualmente a los nanomateriales, aunque éstos no sean explícitamente mencionados. Este escenario abre las puertas a la especulación y libre manipulación del débil marco legislativo alrededor de la investigación y aplicación de las novedosas tecnologías nanoescalares, por parte de las habilidosas transnacionales. Dentro de los esfuerzos normativos internacionales se destacan esfuerzos en los países de la Unión Europea y en los EEUU, que son las potencias mundiales en el campo de la I+D (investigación y desarrollo) de las tecnologías. Es importante destacar que frente a la nanotecnología, "difícilmente se podría establecer una legislación uniforme por el conflicto de interés entre las naciones más desarrolladas en el mundo de la nanotecnología”.

Por lo pronto se está desarrollando una conciencia tardía bajos esfuerzos normativos incipientes en gran parte de los países con mayor desarrollo económico y más preocupados por el impacto de la nanotecnología en el mundo.

\section{Unión Europea}

La Unión Europea, en el 2004, elaboró un documento denominado Hacia una estrategia europea para las nanotecnologías, en el cual se destacan aspectos fundamentales como el fomento a la investigación y desarrollo de Nanotecnología. Desde el punto de vista jurídico se destacan aspectos fundamentales para su regulación, entre los cuales cabe destacar temas fundamentales como: "Registro de patentes, Regulación en salud pública, Protección al medio ambiente y al consumidor, Metrología y normalización, Desarrollo responsable de la Nanotecnología (principios éticos), Cooperación internacional".

\section{Estados Unidos}

El sector privado ha realizado grandes debates sobre los riesgos y beneficios de la nanotecnología. Es el caso de el Center for Responsible Nanotechnology, que es uno de los ejemplos en el mundo en el análisis y divulgación de las ventajas y desventajas de la Nanotecnología. cuya misión es el "Conocimiento del aumento de las ventajas, de los peligros, y de las posibilidades del uso responsable de la Nanotecnología”, desarrollando una revisión cuidadosa de 
las implicaciones ambientales, humanas, económicas, militares, políticas, sociales, médicas, y éticas de la fabricación molecular. Además el Foresight Institute: Fundado por K. Eric Drexler, surge como la agrupación más antigua de la amplia discusión social y científica sobre el impacto potencial de las tecnologías atómicas. Pese a estar decididamente en favor del avance nanométrico (Etc Group, 2003), el Foresight Institute, desarrolló una propuesta de regulación llamada "Lineamientos prospectivos sobre la nanotecnología molecular (Foresight guidelines on molecular nanotechnology), estos lineamientos contienen supuestos de partida, principios y algunas recomendaciones para lo que los autores denominan "desarrollo responsable de la nanotecnología molecular"

\section{Reino Unido}

En el Reino Unido en el año 2004 el Departamento de Comercio e Industria informó la intención de financiar el 50\% del valor de 25 proyectos centrados en la nanotecnología. El total de la inversión por parte del Gobierno es mas más de 22 millones de Euros. El gobierno Británico no sólo fomenta la investigación aplicada en Nanotecnología por medio de su programa de micro y nanotecnología, sino que fomenta la creación de instalaciones que permiten investigar la nanotecnología. Adicionalmente el gobierno aportará más financiación durante el periodo 20042009. The Institute for Science in Society, Fundado en 1999, con sede en Londres, y conocido por sus siglas en inglés (ISIS), es una organización cuyo compromiso no se basa en la remuneración y que trabaja en favor de la responsabilidad social y de las aproximaciones sustentables en el campo científico.

\section{Conclusiones}

"Las tecnologías nanoescalares son concepciones inimaginables hechas realidad hoy en día, aunque para la mayoría de las personas todavía pasan desapercibidas”.

La aparición en escena de la tecnología nanoescalar es un evento considerablemente significativo que nos brinda un potencial sin precedentes para controlar, manipular y moldear toda la materia viva e inerte para obtener un resultado deseado. De esta forma la nanotecnología se estructura en el mundo actual como la llave que abre las puertas a un nuevo universo donde convergen elementos vitales en todos los campos del saber, generando espacios para aprovechar e interrelacionar tecnologías buscando incidir, afectar y beneficiar los procesos vitales humanos, entre ellos, la salud, la vida, la muerte y la enfermedad.

Como conclusión de todo lo citado anteriormente podemos decir lo siguiente:

El análisis del estado actual y de las tendencias mundiales en cuanto a los desarrollos tecnológicos nanoescalares, dejan ver que incluso ante un ambiente financiero tan inestable como el actual, la investigación nanoescalar obtiene una concentración alta de inversiones, innovación y entusiasmo, lo que resulta en una vertiginosa conversión de las tecnologías nanométricas en tecnología "viables" para la incursión en el mercado. De esta forma la industria de la nanotecnología plantea un nuevo renacimiento económico, cultural, social y medioambiental que se estructura de acuerdo a las ventajas que ésta ofrece, en cuanto a la masificación y mejoramiento de los materiales, el desarrollo sostenible y la ganancia en los diferentes ámbitos. Las expectativas que se generan en torno a la nanotecnología evidentemente son realmente prometedoras, y 
cobijan beneficios inconmensurables para el bienestar y la vida de las personas, pero paralelamente y en un ámbito sumamente relegado se encuentran los riesgos e incertidumbres que se generan como consecuencia de la aplicación de dichas tecnologías, es evidente que hace falta bastante información para garantizar un uso seguro de la nanotecnología, y ello requiere que se vincule a los procesos de formación profesional en todas las áreas la nanotecnología como un componente esencial, que vincule a la emergente nanotecnología, procesos críticos cualificados desde la universidad.

Para poder aprovechar las ventajas de la nanotecnologías, se debe efectuar una "adecuada" implementación que le permita a estas novedosas tecnologías acoplarse a las necesidades reales de los modelos sociales de desarrollo, además de generar medios de conectividad, articulación y sinergia entre proponentes, proveedores y usuarios, partiendo de las necesidades existentes del usuario, para acoplar la tecnología de tal manera que ayude a resolver estas necesidades y no genere aspectos desfavorables. Además la implementación de la nanotecnología en la vida cotidiana humana, requiere incluir dentro de los mecanismos de acople la necesidad urgente de generar mecanismos de cualificación, organización y participación que vinculen a la comunidad en la construcción de procesos sociales de transformación, y un componente técnicocientífico que facilite el diseño de modelos de desarrollo e incorporación de las tecnologías nanoescalares según las condiciones, los riesgos, los beneficios y las necesidades de cada persona o grupo social.

El desarrollo de la nanotecnología, especialmente de sus aplicaciones biomédicas y sus impactos en las comunidades marginadas debe entenderse en un contexto social y político más amplio. El punto fundamental es que las nuevas tecnologías no han proporcionado soluciones a los complejos problemas que tienen sus raíces en la pobreza y las desigualdades sociales. Los medicamentos habilitados nanológicamente y las tecnologías de mejoramiento del desempeño humano amenazan desviar, de las necesidades fundamentales de salud, los escasos fondos destinados a la investigación médica y su desarrollo. Es más, el énfasis en intervenciones médicas de alta tecnología amenaza desviar la atención y los recursos de las aproximaciones no médicas que intentan impulsar el desarrollo humano, como intervenciones básicas que conducen a mejoras en salubridad, vivienda, nutrición, educación y empleo pueden, en última instancia, conducir a mucho mayores avances en la salud humana que las aplicaciones nanoescalares biomédicas de punta.

El énfasis en el mejoramiento del desempeño humano, no sólo amenaza redirigir los escasos fondos de investigación y desarrollo en salud, desviándolos de las necesidades esenciales de salud de la gente marginada, sino que a fin de cuentas creará una "brecha de capacidades". Al igual que la brecha digital, la brecha de capacidades ensanchará el abismo entre el Norte y el Sur, entre ricos y pobres. Es probable que en el contexto social y político que prevalece, la introducción de penetrantes tecnologías del refinamiento humano provoque la marginación de más grupos de personas.

Hay muchas cuestiones fundamentales sin respuesta, en relación a los impactos ambientales y de salud de los materiales nanoescalares que ya se usan en el desarrollo de medicamentos de innovación. Aunque muchos promotores prometen que la nanotecnología nos brindará revolucionarios avances en la salud, mejorando nuestra calidad de vida y hasta prolongado nuestra existencia, es también posible que algunas de sus aplicaciones introduzcan nuevos riesgos a la salud humana. Es prácticamente desconocida la toxicología de los materiales nanoscópicos 
diseñados, y de los estudios toxicológicos que se condujeron con la misma sustancia formulada en partículas de mayor escala no pueden extrapolarse datos. Los recientes estudios toxicológicos sobre los impactos ambientales y de salud de las nanopartículas fabricadas indican que hay razones para preocuparnos. $\mathrm{Y}$, pese al hecho de que algunos productos nanoescalares ya se comercializan (incluidos algunos medicamentos nanológicos), ningún gobierno del mundo ha desarrollado regulaciones que respondan a los aspectos de seguridad que implican los materiales nanométricos.

\section{Recomendaciones generales}

Teniendo en cuenta el desarrollo disruptivo de las nanotecnologías y que la comercialización de productos nanométricos o con componentes nanométricos han empezado y se amplificará en los próximos años, consideramos fundamental continuar vigilando atentamente la evolución de estas nuevas tecnologías y así lograr investigar y generar conocimiento actualizado en referencia a los posibles y reales impactos que resulten de la aplicación de dichas tecnologías. Desde la universidad se debe establecer una terminología y una nomenclatura científicas comunes, con el fin de determinar procedimientos y normas adecuadas a su aplicación, y continuar el desarrollo de la investigación y la difusión de sus resultados.

Teniendo en cuanta los niveles de interacción de las aplicaciones nanotecnológicas, se recomienda la creación de programas de investigación transdisciplinaria sobre los impactos de las nuevas tecnologías y sobre la evaluación del riesgo asociado a las nanotecnologías que tenga en cuenta sus dimensiones éticas y sociales.

El principio precautorio juega un papel importante en el proceso de creación y de preparación de medicamentos y de terapias con componentes nanotecnológicos. Esta característica incita a proseguir con la investigación y a documentar los efectos potencialmente positivos y negativos de las aplicaciones nanotecnológicas en el campo de los cuidados de salud para poder evaluar mejor las consecuencias las personas y en el funcionamiento del sistema de salud en general.

\section{Recomendaciones Sociopolíticas - Económicas}

A los Ministerios y Organismos gubernamentales, se les recomienda que inicien un proceso de información y debate con la población para establecer, con total transparencia, las preocupaciones científicas, económicas, sociales y éticas asociadas a las nanotecnologías.

Las iniciativas en inversión deben aplicarse durante la elaboración de una estrategia nacional de desarrollo de las nanotecnologías, esto con el fin de responder a las necesidades económicas y sociales propias de Argentina y considerar, de manera específica, los cuestionamientos e implicaciones sociales relativas a estas tecnologías.

Los cambios que se pueden presentar como resultado de la aplicación nanotecnológicas resultan en desafíos mayores con respecto a la formación de la mano de obra y al sistema de educación. La recomendación va dirigida a contemplar a los trabajadores como individuos de la sociedad vulnerables, en las medidas que son las primeras víctimas de las transformaciones del mercado laboral que conlleva la emergencia de nuevas tecnologías de producción industrial. 
Se recomienda al Gobierno Nacional tener en cuenta y sentar precedente con respecto a la normativa que regule las patentes que se generan para los procesos e innovaciones nanotecnológicas; es evidente que en los nanoprocesos se patenta a un nivel donde no existen "innovaciones" que patentar, sino que simplemente se descubren los átomos, las moléculas y/o los genes que otorgan determinada característica a una estructura u organismo vivo. La Argentina siendo beneficiario de una gran biodiversidad debe conservar y prevenir que dicha riqueza caiga en manos de individuos, que solo harán uso de ella para un bien particular.

\section{Recomendaciones Medioambientales}

Orientados por el principio de precaución y desde una perspectiva de desarrollo sostenible, se recomienda que se tengan en cuenta todas las fases del ciclo de vida de un producto que contenga nanotecnología o elementos nanométricos en todas las investigaciones y políticas medioambientales, y así evitar cualquier consecuencia nociva de esta innovación tecnológica en la salud y en el ecosistema.

Se resalta la importancia de multiplicar la investigación sobre las posibles consecuencias de las nanotecnologías para determinar las substancias que podrían ser nocivas para el medio ambiente. Esta recomendación precisa el compromiso de investigadores, industriales y organismos públicos. Se hace necesario que el gobierno intervenga por medio de políticas para que ministerios desde la administración en el campo de la salud y del medio ambiente establezcan mecanismos necesarios para la evaluación de la toxicidad de los procesos y de los productos que contengan nanotecnologías como requisito anterior a la autorización de su comercialización.

Se recomienda poner a consideración y determinar la implementación de medidas de prevención adecuadas y relacionadas con el conocimiento del ciclo de vida de los productos que portan las nanotecnologías, y como éstos contribuirán a proteger la salud y la seguridad alimentaria y sean partícipes en el desarrollo responsable del sector agro.

Se hace necesario que los actores implicados en los sistemas de producción agroindustrial, establezcan un sistema de vigilancia permanente de los efectos potenciales de los productos que contengan nanotecnologías sobre el medio ambiente y las personas, especialmente cuando no sea posible calcular los efectos antes de su comercialización.

\section{Recomendaciones Socioculturales}

La ausencia evidente de información y educación con respecto a lo que es y las características de las aplicaciones nanotecnológicas, nos lleva a preguntarnos lo siguiente: ¿Cómo tomar decisiones informadas, como legislador, investigador, empresario, trabajador o ciudadano si no existe una comprensión común de lo que son las nanotecnologías?, la recomendación entonces va dirigida a solucionar dicho cuestionamiento, informando y difundiendo por medio de una construcción social los conocimientos necesarios para afrontar esta nueva revolución tecnológica. Los productos con aplicaciones de nanotecnología que se encuentran en el mercado deben tener una regulación inmediata y confiable. Se debe tener en cuenta si vale la pena sacrificar la salud por una prenda de vestir, un bloqueador, un electrodoméstico etc. 
Es importante tomar medidas de precaución que eviten la acumulación de riesgos y de daños al ser humano a la hora de acceder a un artículo. Es importante tener en cuenta medidas de precaución con todos los electrodomésticos, con el fin de evitar riesgos irreparables y contribuir a la consideración de manera prioritaria de la salud del consumidor y el medio ambiente. La regulación sobre los productos cosméticos debe ser inmediata y el principio de precaución se debe tener en cuenta frente a estos por parte de los usuarios, es importante expandir la comunicación de los efectos negativos ocasionados por nano partículas de oxido de zinc entre otras. La sociedad consumidora de alimentos debe revisar minuciosamente las indicaciones nutricionales y tener presente que existen productos en el mercado con aplicaciones de nanotecnología que pueden generarle a largo plazo problemas de salud.

\title{
Referencias Bibliográficas
}

Booker, R.; D. Boysen, E. ( 2005). Nanotechnology for dummies. $3^{\circ}$ Edition. Wiley Publishing, Inc. Chemistry of Materials. ( 1980). Revista The American Chemical Society. New York.

Drexler, K. E. (2002). Molecular machinery, manufacturing, and computing. $5^{\circ}$ Edition. New York: John Wiley \& Sons, Inc.

Feynman, R. (1959). Quantum computing, nanotechnology, as in molecular machines. $2^{\circ}$ Edition. By A Chen.

Rejeski, D. (2009). Nanotechnology and consumer products. $3^{\circ}$ Edition. 4330 East West Highway Bethesda, M.

Shriver, E. A. (2005). Química Inorgánica. Bookman. 4 Edition. Kotz \& Trelchel.

Tabata, Y. (2005). Nanomaterials of drug delivery systems for tissue regeneration. Bock. $2^{\circ}$ Edition. S. A. Atkins F M.

(2003). Methods in Molecular Biolog. Bock. 4 Edition. S. A. Atkins F M.

Whitesides, G. M. (2003). The right size in nanobiotechnology. $1^{\circ}$ Edition. Cambridge: Department of Chemistry and Chemical Biology, Harvard University.

(2001). Nature Biotechnology. 1 Edition. Cambridge: Department of Chemistry and Chemical Biology, Harvard University.

Yong, C. (2006). High-density molecular electronic memory. $1^{\circ}$ Edition. By S Patil.

\begin{abstract}
Summary: This article summarizes the state of development of nanoscience and nanotechnology today. The effects on education. The latest scientific findings in all industrial areas applicable to nanotechnology. The development of materials in the textile industry with the use of nanotechnology and nano-particles that create nanoscale structures such as yarns, fabrics and garments. Nanotechnology products used in dry-cleaners, stamping and laundries. New technical and legal standards for the development, production, use and protection of the new science. The advantages and macro and micro economic performance.
\end{abstract}

Key words: nano particles - Nanoscience - Nanotechnology - molecules - vibrational energy. 
Resumo: Este artigo resume o estado de desenvolvimento da Nanociência e a Nanotecnologia na atualidade. Os efeitos na educação. Os descobrimentos científicos mais recientes em todas as áreas industriais aplicadas à Nanotecnologia. O desenvolvimento de materiais na indústria textil com a utilização de nanotecnologia e nano partículas que criam estruturas nanométricas, tais como hilados, texidos e indumentárias. Produtos nanotecnológicos utilizados nos locais de lavagem à seco, estamperias e lavanderias. Novas normas técnicas e jurídicas para o desenvolvimento, produção, utilização e proteção da nova ciência. As vantagens e o desempenho macro e micro econômicos.

Palavras chave: energia vibracional - nano partículas - Nanociência - Nanotecnologia - moléculas. 